\title{
MICROLENS ARRAY FABRICATION ON FUSED SILICA BY LIBBH TECHNOLOGY WITH $\mathrm{CO}_{2}$ LASER SMOOTHING
}

\author{
R. A. ZaKoldaeV, G. K. KostyuK, V. V. Koval, \\ M. M. SERGEEV, V. S. RYMKeVICH, E. B. YAKOVLEV \\ ITMO University, 197101, St. Petersburg, Russia \\ E-mail: zakoldaev@gmail.com
}

\begin{abstract}
A new technology for microlens array fabrication is presented. The technology is based on creation of the initial microstructures on fused silica by laser indirect method, and the following reflow process of these structures made by $\mathrm{CO}_{2}$ laser action. Microlens arrays with diameter of microlens equal to $150 \mu \mathrm{m}$ are fabricated. The focal length of microlens varies from 5 up to $5 \mathrm{~mm}$. Profiles of formed microlens correspond to circle equation.
\end{abstract}

Ключевые слова: fused silica microstructuring, microlens array, $\mathrm{LIBBH}, \mathrm{CO}_{2}$ laser

Introduction. At present different arrays of microoptical elements are traditionally used for transformation and processing of optical signals, for fiber-optical connections and integrated optical control systems [1] as well as to transform of intensity distribution in laser technology [2, 3]. As the array of microoptical elements means a set of modified regions, located in a certain order on glass surface $[2,4]$ and can be called microlens array (MLA). Such MLAs have a special arrangement and a given filling rate within the array, all these specifications depend on the problem to be solved with the final array.

Not only optical-physical specific requirements are imposed on MLA in particular application, but also requirements on the surface quality in general. Particular attention is paid to the fabrication of MLAs on materials of traditional optics as silicate glass [5]. Thus, the developers' preferences are given to fused silica, which can be characterized by high light transmittance in wavelength range of $200-2500 \mathrm{~nm}$ and high chemical, thermal, and radiation resistance [6].

Among the traditional technologies of MLAs fabrication on glass surface, the best known technologies are: photolithography [7], ion etching [8], hot embossing process [9], and so on. These technologies can be characterized not only by high quality of fabricated MLAs and high reproducibility, but also use multistage processing; manufacturing of MLAs with low numerical aperture (NA) presents difficulties when the technology is employed [7]. Currently, great attention is paid to MLAs fabrication with the usage of laser technology. It is also called as direct laser beam writing, which is based on strong absorption of $\mathrm{CO}_{2}$ laser radiation [10], UV radiation [11] by glass , or on interaction with ultrashort laser pulses [12].

Combined laser-induced technologies based on strong absorption of laser radiation by inorganic $[13,14]$ or organic $[15,16]$ solutions and metals $[17,18]$ contact with the back side of the glass plate are widely spread today. The most popular technologies are laser-induced backside wet etching (LIBWE) [16, 19-22], laser-induced backside dry etching (LIBDE) [17, 18, 23], laser induced plasma assisted ablation (LIPAA) [24-26], and lased-induced black-body heating (LIBBH). The last one has been developed at Laser Technology Department of ITMO University [27-31]. Various arrays of microoptical elements formed on fused silica surface according to this technology include random phase plates [27], sinusoidal diffractive gratings [27, 29, 30], and MLAs [29, 31]. It is important to note that the square of the arrays may be high (up to $100 \mathrm{~mm}^{2}$ and more) and depends on the used laser setup. It is worthwhile to note that the formed MLAs have a special profile - an almost flat top of each microlens (rounded trapeze) in the array, thus the microlens has low NA value [31]. 
In this case the microlens profile may need to be modified (made spherical) with an additional processing stage, such as a reflow process. The thermal reflow process in a furnace is possible if the array of MLAs is formed on glass with low transition temperature. In case with fused silica it is a problem to achieve any steady operation with a temperature ranging from 1600 up to $1700{ }^{\circ} \mathrm{C}$. For the MLAs formed on fused silica, it would be better to perform the reflow process using $\mathrm{CO}_{2}$ laser radiation [32]. As it is shown in $[32,33]$, the thermal reflow process is achieved at the power density of $\sim 10^{4} \mathrm{~W} / \mathrm{cm}^{2}$. However, in most cases it leads to stresses across the reflowed MLA. The situation changes if the treatment is carried out in the ablation regime $\left(\sim 10^{5} \mathrm{~W} / \mathrm{cm}^{2}\right)$ [34]. It not only allows to reshape the MLA relief, but also to control the microlens sag and therefore to manage its optical characteristics.

This paper presents a two-step method of MLAs fabrication on fused silica plates. It is a combination of LIBBH technology, that allows to create the initial microstructures in a simple way, and the reflow process of these structures with $\mathrm{CO}_{2}$ laser beam scanning (in the ablation regime) along the array surface in order to reshape them and manage the future microlens optical characteristic.

Experiment. MLA fabrication. The flat-parallel fused silica plates is used as the samples (with dimensions $15 \times 15 \times 1 \mathrm{~mm}^{3}$ ) for the MLAs formation. All glass plates used in the experiment have the surface roughness equal to $R_{a}=10 \mathrm{~nm}$. The experimental setup for LIBBH technology is shown schematically in Fig. $1, a, b$. The ytterbium fiber laser $1(\lambda=1,064 \mu \mathrm{m}$, $\tau \sim 50 \ldots 200 \mathrm{~ns}, v=10 \ldots 100 \mathrm{kHz}$ ) is used as a light source. The laser beam is scanned by two galvanometer-scanning modules 2 and focused by a telecentric lens $3(f=135 \mathrm{~mm})$ on the back surface of the fused silica plate 4 , which is placed on a polished pressed graphite plate 5 . Fused silica 4 and the graphite plate 5 are fixed on the coordinate table 6 . The power density in the micromachining region ranges up to $10^{7}-10^{8} \mathrm{~W} / \mathrm{cm}^{2}$.

a)

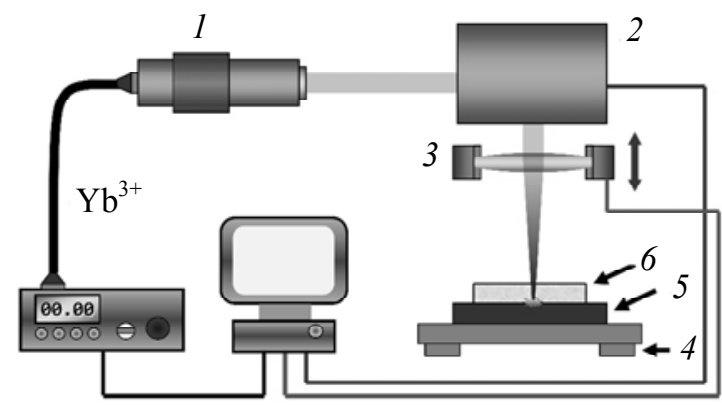

b)

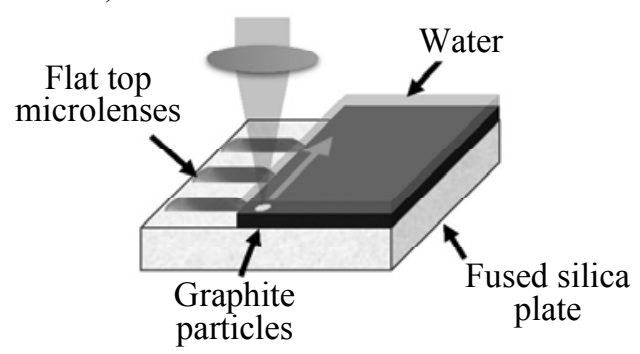

c)

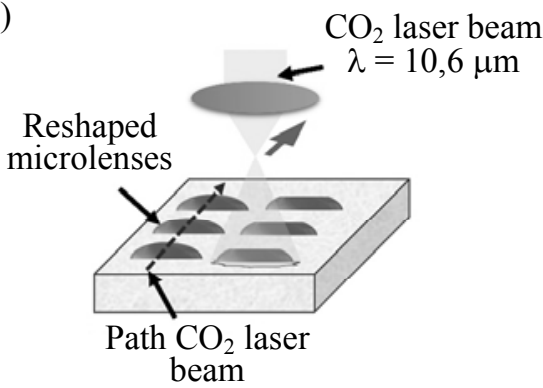

Fig. 1

The fused silica surface is absolutely coated by graphite particles after laser irradiation. As a result, cleaning process of fused silica is necessary to be carried out on the same experimental setup, but at a different laser regime. We remove the graphite plate and turn the fused silica plate upside down (Fig. 1, b). The best cleaning result is achieved with laser wet cleaning, when a thin water layer is deposited on the contaminated area [24]. The laser wet cleaning parameters are the following: $v=30 \mathrm{kHz}, v=2500 \mathrm{~mm} / \mathrm{s}, P=6 \mathrm{~W}$. 
The formed microstructures on fused silica glass are investigated with the optical microscope Carl Zeiss Axio Imager A1 in reflective light (Fig. 2, a) and its profiles are measured with the profilometer (Hommel Tester T8000) (Fig. 2, b).
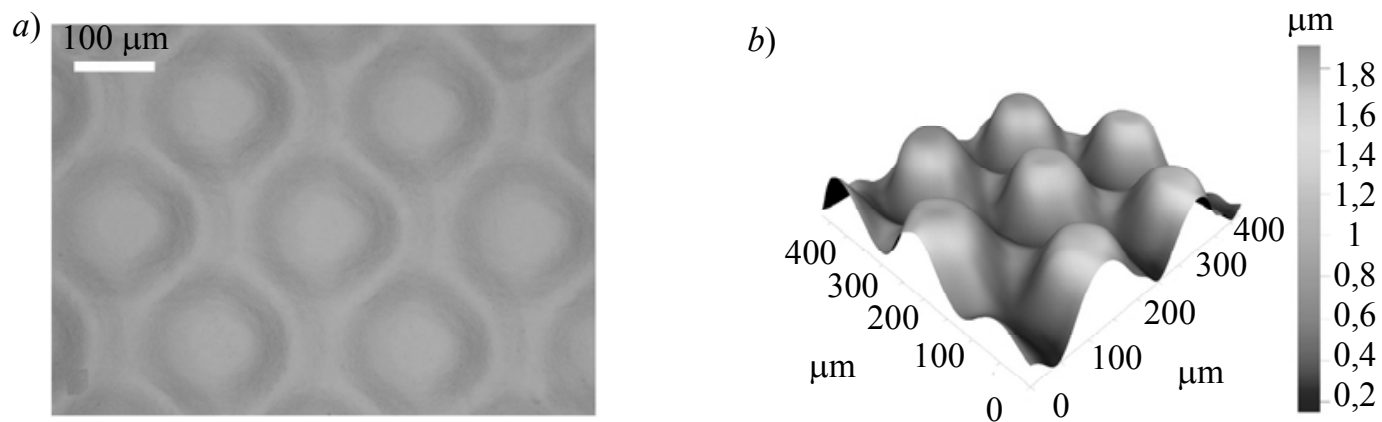

Fig. 2

The reshaping of these structures is performed with the quasi-cw $\mathrm{CO}_{2}$ laser (which is called "TROTEC Speedy-500") having maximum power equal to $100 \mathrm{~W}$ and the flying optic with the focusing lens $(f=50 \mathrm{~mm})$. The process of microstructures reflowing is schematically shown in Fig. $1, c$. The following parameters of $\mathrm{CO}_{2}$ laser machining provided the result in the reshaping of the microstructures (i.e. made their profile spherical): laser beam diameter $(d=1 \mathrm{~mm})$, average power $P=45 \mathrm{~W}$, scan speed $(v=20 \mathrm{~mm} / \mathrm{s})$ and overlapping $(80 \%)$. Results of microscopic study of the formed MLA after the reflowing process and its profile are shown in Fig. 3: $a$ - three-dimensional profile after $\mathrm{CO}_{2}$ laser smoothing ( 3 passes); $b-$ microlenses profile comparison before and after $\mathrm{CO}_{2}$ laser smoothing (3 passes).

a)

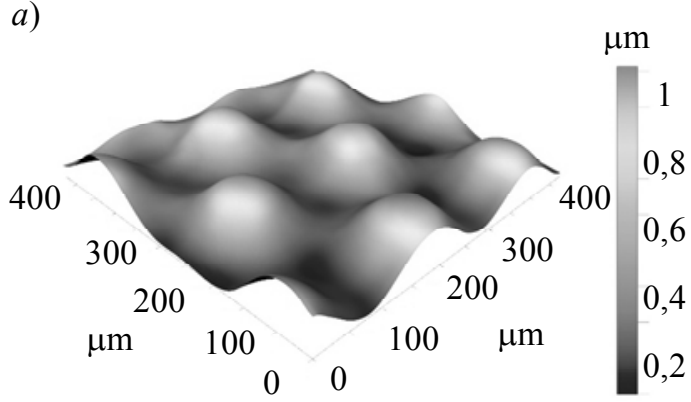

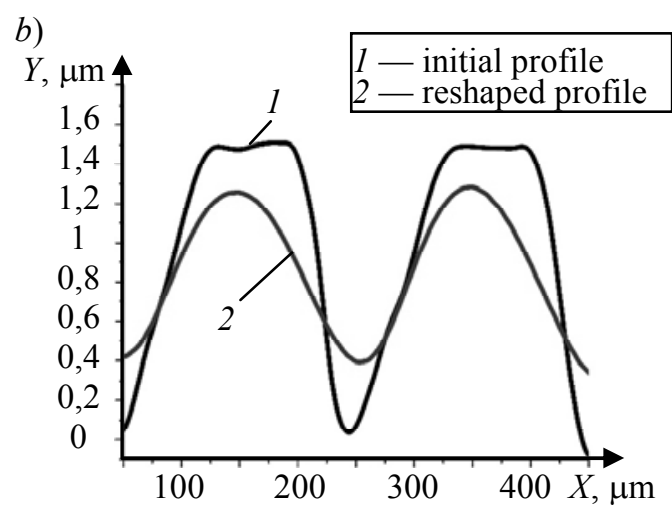

Fig. 3

MLA optical characteristics. The MLAs focal length $\left(f_{\mathrm{MLA}}\right)$ and focal spot diameter $\left(d_{f}\right)$

a)

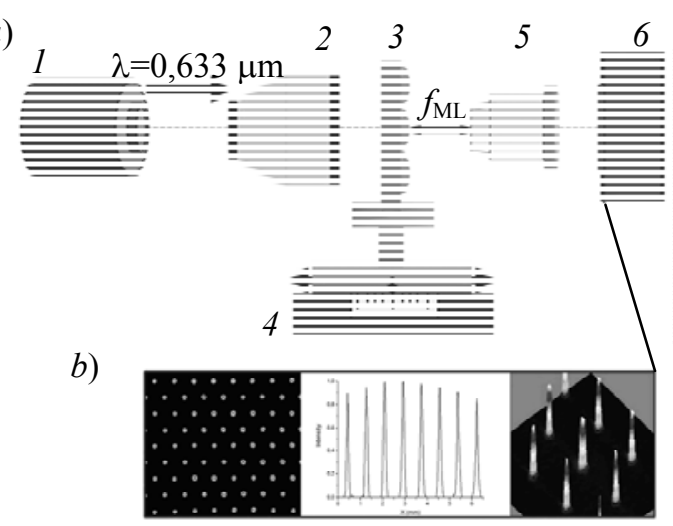

Fig. 4 are measured with the experimental setup shown in Fig. 4, $a$. The scheme works in the following way: the radiation of He-Ne-laser $1(\lambda=0,633 \mu \mathrm{m})$ goes through the telescopic system 2 expanding laser beam to $6 \mathrm{~mm}$ and reaches the MLA 3. The MLA 3 is fixed on the coordinate table 4 with microreplacement mechanism, which allows to move the MLA 3 along the optical axis with an accuracy equal to $\pm 1 \mu \mathrm{m}$. The CCD camera 5,6 is used to find the focal plane of the MLA 3. The results of the investigation-intensity distribution on CCD camera are shown in Fig. $4, b$. Thus some basic parameters of the microlenses such as focal length and the size of the focal spot are determined (see Table). 
Characteristics of the microlenses

\begin{tabular}{|l|c|c|c|c|}
\hline \multicolumn{1}{|c|}{ Processing regime } & $\begin{array}{c}\text { Without } \mathrm{CO}_{2} \text { laser } \\
\text { smoothing }\end{array}$ & 1 pass & 2 passes & 3 passes \\
\hline Sag $h_{\mathrm{ML}}, \mu \mathrm{m}$ & 1,7 & 1,2 & 1 & 0,8 \\
\hline Radius of curvature $R, \mathrm{~mm}$ & - & 2,3 & 2,8 & 3,5 \\
\hline Focal length $f_{\mathrm{ML}}, \mathrm{mm}$ & 35 & 5,0 & 6,1 & 7,6 \\
\hline Focal spot size $d_{f} \mu \mathrm{m}$ & 110 & 64 & 78 & 86 \\
\hline Numerical aperture & 0,002 & 0,015 & 0,012 & 0,009 \\
\hline
\end{tabular}

Results and discussion. The power density of the incident $\mathrm{CO}_{2}$ laser radiation on the microstructured glass surface may be estimated according to the expression from the work [35]:

$$
q_{0}=\frac{P}{\left(\frac{\pi d^{2}}{4}\right) f \tau} .
$$

At the average power $(P=45 \mathrm{~W})$ and with the beam diameter mentioned above, the power density can reach the value equal to $q_{0} \sim 10^{5} \mathrm{~W} / \mathrm{cm}^{2}$.

To evaluate the temperature in the center of irradiated area, the following expression may be used [36]:

$$
T=\frac{2 A q_{0} \sqrt{a \tau}}{k \sqrt{\pi}}+T_{0},
$$

where $\mathrm{A}$ - the absorbance of the fused silica plate for wavelength of $10,6 \mu \mathrm{m}\left(\mathrm{A}_{\mathrm{Q}} \sim 0,9\right)$; $a-$ thermal conductivity $\left(a=8,4 \cdot 10^{-7} \mathrm{~m}^{2} \cdot \mathrm{s}^{-1}\right) ; k$ - heat diffusion $\left(k=1,35 \mathrm{~W} \cdot(\mathrm{m} \cdot \mathrm{K})^{-1}\right) ; T_{0}$ - initial temperature $\left(T_{0}=298 \mathrm{~K}\right)$ [37]. Thus, the temperature on the fused silica surface in the center of the irradiated area may reach the value equal to $T \sim 2200 \mathrm{~K}$. This implies that our regime of $\mathrm{CO}_{2}$ laser machining corresponds to ablation regime [38].

We analyzed the microlens morphological characteristics using the profilometry data and estimated the optical properties of the microlenses. Since we knew the curve radius of the microlens, the microlens focal length $\left(f_{\mathrm{ML}}\right)$ and diameter of focal spot $\left(d_{f}\right)$ may be calculated according to Rayleigh criterion [39]:

$$
f_{\mathrm{ML}}=\frac{R}{n-1} ; d_{f}=2,44 \frac{\lambda f_{\mathrm{ML}}}{d_{\mathrm{ML}}},
$$

where $n-$ the refraction index of fused silica for wavelength $\lambda=0,633 \mu \mathrm{m}(n=1,46) ; d_{\mathrm{ML}}-$ the microlens diameter $\left(d_{\mathrm{ML}}=150 \mu \mathrm{m}\right)$.

For the regime with 3 passes of $\mathrm{CO}_{2}$ laser beam the values of the focal length and the diameter of focal spot are $f_{\mathrm{ML}}=7,66 \mathrm{~mm}$ and $d_{f}=78,80 \mu \mathrm{m}$.

The measured and calculated results are in a good agreement (see Table). The profile of microlenses after $\mathrm{CO}_{2}$ reflowing coincides with the profile corresponded to the equation of the circle (Fig. 5).

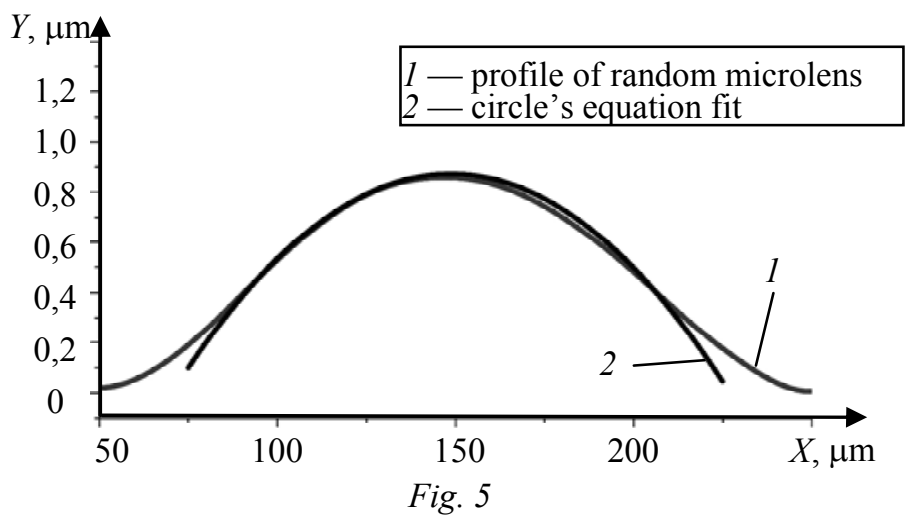


Conclusion. A new method for MLA fabrication on fused silica is demonstrated. It is a combination of $\mathrm{LIBBH}$ technology with additional reflowing stage made by $\mathrm{CO}_{2}$ laser irradiation. It is shown that the ablation regime at the reflow process allows to reshape microstructures without any residual stresses and manage the future microlens optical characteristic. The formed microlens profiles corresponds to the circle equation. As for the optical characteristics of the MLAs, the results show satisfactory coincidence between the experimental and theoretical results.

Authors are very grateful to Natalia Wierzbicki and Anna Otkeeva for assistance in MLA analysis by profilometry and $\mathrm{CO}_{2}$ laser reflowing.

The study was supported by a grant from leading universities of the RF (subsidy 074-U01) and RSF agreement № 14-12-00351.

\section{СПИСОК ЛИТЕРАТУРЫ}

1. McCormick F. et al. Optical interconnections using microlens arrays // Optical and Quantum Electronics. 1992. Vol. 24, N 4. P. 465- 477.

2. Dickey F. M. Laser Beam Shaping: Theory and Techniques. CRC Press, 2014.

3. Dickey F. M., Lizotte T. E. Imaging micro lens array beam integrator system design for fiber injection // SPIE Opt. Engineering \& Applications; Intern. Soc. for Optics and Photonics. 2011.

4. Dames $M$. P. et al. Efficient optical elements to generate intensity weighted spot arrays: design and fabrication // Appl. Opt. 1991. Vol. 30, N 19. P. 2685-2691.

5. Ottevaere H. et al. Comparing glass and plastic refractive microlenses fabricated with different technologies // J. of Optics A: Pure and Applied Optics. 2006. Vol. 8, N 7. P. S407.

6. Bansal N. P., Doremus R. H. Handbook of Glass Properties. Elsevier, 2013.

7. Roy E. et al. Microlens array fabrication by enhanced thermal reflow process: Towards efficient collection of fluorescence light from microarrays // Microelectronic Engineering. 2009. Vol. 86, N 11. P. 2255-2261.

8. Langridge M. T. et al. The fabrication of aspherical microlenses using focused ion-beam techniques // Micron. 2014. Vol. 57. P. $56-66$.

9. Chang C., Yang S. Y., Sheh J. A roller embossing process for rapid fabrication of microlens arrays on glass substrates // Microsystem Technologies. 2006. Vol. 12, N 8. P. 754-759.

10. Wakaki M., Komachi Y., Kanai G. Microlenses and microlens arrays formed on a glass plate by use of a CO 2 laser // Appl. Opt. 1998. Vol. 37, N 4. P. 627-631.

11. Endert H., Pätzel R., Basting D. Excimer laser: a new tool for precision micromachining // Optical and Quantum Electronics. 1995. Vol. 27, N 12. P. 1319-1335.

12. Guo R. et al. Microlens fabrication by means of femtosecond two photon photopolymerization // Opt. Express. 2006. Vol. 14, N 2. P. $810-816$.

13. Kopitkovas G. et al. Laser processing of micro-optical components in quartz // Appl. Surface Sci. 2007. Vol. 254, N 4. P. 1073-1078.

14. Wang J., Niino H., Yabe A. Micromachining of quartz crystal with excimer lasers by laser-induced backside wet etching // Appl. Phys. A. 1999. Vol. 69, N 1. P. S271-S273.

15. Ding $X$. et al. Laser-induced back-side wet etching of fused silica with an aqueous solution containing organic molecules // Appl. Phys. A. 2002. Vol. 75, N 3. P. 437—440.

16. Wang J., Niino H., Yabe A. One-step microfabrication of fused silica by laser ablation of an organic solution // Appl. Phys. A. Materials Science \& Processing. 1999. Vol. 68, N 1. P. 111-113.

17. Smausz $T$. et al. Influence on the laser induced backside dry etching of thickness and material of the absorber, laser spot size and multipulse irradiation // Appl. Surface Sci. 2007. Vol. 254, N 4. P. 1091-1095.

18. Chao H. et al. Fabrication of microtransmittance grating using laser induced backside dry etching // J. of Laser Applications. 2012. Vol. 24, N 1. P. 012001. 
19. Niino $H$. et al. Surface micro-fabrication of silica glass by excimer laser irradiation of organic solvent // J. of Photochem. and Photobiol. A: Chemistry. 2003. Vol. 158, N 2. P. 179-182.

20. Niino $H$. et al. Imprinting by hot embossing in polymer substrates using a template of silica glass surface-structured by the ablation of LIBWE method // Appl. Phys. A. 2004. Vol. 79, N 4-6. P. 827-828.

21. Kawaguchi $Y$. et al. Rapid prototyping of silica glass microstructures by the LIBWE method: Fabrication of deep microtrenches // J. of Photochem. and Photobiol. A: Chemistry. 2006. Vol. 182, N 3. P. 319-324.

22. Niino $H$. et al. Surface micro-structuring of silica glass by laser-induced backside wet etching with ns-pulsed UV laser at a high repetition rate // J. of Laser Micro/ Nanoengineering. 2006. Vol. 1, N 1. P. 39_43.

23. Норр B. et al. Comparative study of different indirect laser-based methods developed for microprocessing of transparent materials. JLMN // J. of Laser Micro/Nanoengineering. 2010. Vol. 5, N 1. P. 80-85.

24. Hanada Y. et al. Development of practical system for laser-induced plasma-assisted ablation (LIPAA) for micromachining of glass materials // Appl. Phys. A. 2004. Vol. 79, N 4 -6. P. 1001-1003.

25. Hong $M$. et al. Laser-induced-plasma-assisted ablation for glass microfabrication // Intern. Symp. on Photonics and Applications; Intern. Soc. for Optics and Photonics. 2001.

26. Hong M. et al. Laser microfabrication of transparent hard materials and signal diagnostics // Appl. Surface Sci. 2002. Vol. 186, N 1. P. 556-561.

27. Kostyuk G. K. et al. Fast microstructuring of silica glasses surface by NIR laser radiation // Optics and Lasers in Engineering. 2015. Vol. 68. P. 16-24.

28. Sergeev M. M. et al. Laser induced passivation of porous glass to protect it from chemical degradation and aging // Protection of Metals and Physical Chemistry of Surfaces. 2015. Vol. 3. P. 427-435.

29. Zakoldaev $R$. et al. Laser-induced black-body heating (LIBBH) as a method for glass surface modification // J. of Laser Micro/Nanoengineering. 2015. Vol. 10, N 1. P. 15-19.

30. Kostyuk G. et al. Laser-induced glass surface structuring by LIBBH technology // Optical and Quantum Electronics. 2016. Vol. 48, N 4. P. $1-8$.

31. Kostyuk G. et al. Microlens array fabrication on fused silica influenced by NIR laser // Appl. Phys. B. 2016. Vol. 122, N 4. P. $1-8$.

32. Wlodarczyk K. L. et al. Laser smoothing of binary gratings and multilevel etched structures in fused silica // Appl. Opt. 2010. Vol. 49, N 11. P. 1997-2005.

33. Choi H.-K. et al. Formation of cylindrical micro-lens array on fused silica glass surface using CO2 laser assisted reshaping technique // Optics \& Laser Technology. 2015. Vol. 75. P. 63-70.

34. Elhadj S. et al. Laser-based dynamic evaporation and surface shaping of fused silica with assist gases: a path to rimless laser machining // Appl. Phys. B. 2013. Vol. 113, N 3. P. 307-315.

35. Fundamentals of Laser-Assisted Micro- and Nanotechnologies / Ed: V. P. Veiko, V. I. Konov. Springer, 2014. P. 149-171.

36. Metev S. M., Veiko V. P. Laser-Assisted Microtechnology. Springer Science \& Business Media. 2013.

37. Palik E. D. Handbook of optical constants of solids // Academic Press. 1998. Vol. 3.

38. Markillie G. A. et al. Effect of vaporization and melt ejection on laser machining of silica glass micro-optical components // Appl. Opt. 2002. Vol. 41, N 27. P. 5660-5667.

39. Born M., Wolf E. Principles of Optics: Electromagnetic Theory of Propagation, Interference and Diffraction of Light. CUP Archive. 2000

Roman A. Zakoldaev

Galina K. Kostyuk

Vladislav . Koval

\section{Data on authors}

- ITMO University, Department of Laser Technologies; Research Engineer; E-mail: zakoldaev@gmail.com

- ITMO University, Department of Laser Technologies; Head Teacher; E-mail: kostyuk@lastech.ifmo.ru

- ITMO University, Department of Laser Technologies; E-mail: kovalvlad@yandex.ru 
Maxim M. Sergeev

- ITMO University, Department of Laser Technologies; Research Engineer; E-mail: maks-sv-32@yandex.ru

Vladimir S. Rumkevich - Student; ITMO University, Department of Laser Technologies

Evgeny B. Yakovlev _ - Dr. Sci., Professor; ITMO University, Department of Laser Technologies; E-mail: yak@lastech.ifmo.ru

Received 08.02.16 г

For citation: Zakoldaev R. A., Kostyuk G. K., Koval V. V., Sergeev M. M., Rymkevich V. S., Yakovlev E. B. Microlens array fabrication on fused silica by LIBBH technology with $\mathrm{CO}_{2}$ laser smoothing // Izv. vuzov. Priborostroenie. 2016. Vol. 59, N 5. P. 400-406 (in English).

DOI: 10.17586/0021-3454-2016-59-5-400-406 